\title{
VNT and EGR Technologies for a Turbocharged Diesel Engine
}

\author{
Junhua $\mathrm{Wu}$ \\ School of Automobile and Traffic Engineering \\ Nanjing Forestry University \\ Nanjing , China \\ wj_h@163.com \\ Fushan Zuo \\ School of Automobile and Traffic Engineering \\ Nanjing Forestry University \\ Nanjing , China \\ zuofushan@163.com
}

\author{
Yonghui Zhang \\ School of Automobile and Traffic Engineering \\ Nanjing Forestry University \\ Nanjing , China \\ zyh@njfu.edu.cn
}

\begin{abstract}
In this study an experimental investigation was carried out on a turbocharger with variable nozzle turbine (VNT) and exhaust gas recirculation (EGR) system reducing emissions of a direct injection diesel engine. In the EGR system, the exhaust gas was tapped off before the turbine, cooled, and mixed with the intake air after the compressor. A positive pressure difference across the EGR circuit was set up by using a VNT turbocharger, a venturi pipe positioned in the intake manifold such as to provide extra suction power to the EGR gases. The emissions behavior and efficiency with the EGR system were tested in a number of engine working points. The results indicated that the engine could achieve a perfect performance in all speed range with applying of the turbocharger with VNT. The torque was improved greatly at any speed, especially at low speeds; The fuel consumption was improved too; The nitric oxides $\left(\mathrm{NO}_{\mathrm{X}}\right)$ emissions was reduced by large scale by EGR system. With using VNT and venturi pipe, the EGR area and the maximum EGR rate could be enlarged, the $\mathrm{NO}_{\mathrm{X}}$ emissions was reduced to lower level.
\end{abstract}

Keywords-Variable nozzle turbine; Turbocharger; Emissions, EGR

\section{INTRODUCTION}

The emissions legislation for diesel engine across the world has continuously sharpened. The primary target of this legislation has been the reduction of the emissions of nitric oxides $\left(\mathrm{NO}_{\mathrm{X}}\right)$ and of particulate matter $(\mathrm{PM})$ by these engines ${ }^{[1]}$.

It is difficult to reduce $\mathrm{NO}_{\mathrm{X}}$ and $\mathrm{PM}$ emissions simultaneously owing to $\mathrm{NO}_{\mathrm{X}} / \mathrm{PM}$ trade-offs. One useful $\mathrm{NO}_{\mathrm{X}}$ reduction technique is exhaust gas recirculation (EGR) ${ }^{[2]}$. Research at TNO on EGR-technology for HD diesel engines has shown before that with appropriate hardware and a dedicated control strategy very low levels of NOx and PM emissions can be achieved while maintaining competitive fuel economy and transient behavior ${ }^{[3]}$. Other researches show that the $\mathrm{NO}_{\mathrm{X}}$ emissions of the engine can be reduced by large scale without increasing in smoke or fuel consumption while maintaining an adequate excess air ratio ${ }^{[4-6]}$. EGR has already been used on naturally aspirated diesel engine for many years. While there are many difficulties for EGR technology applying on turbocharged engine. A larger EGR rate is needed in turbocharged diesel engine. While the pressure before turbine is lower than that of after compressor in many operating points. It would be an obstacle for the gas flow of high pressure routine EGR system circuit. In most cases there are solutions for setting up EGR in a HP (high pressure)-EGR circuit: either through modified valve timing (Miller-timing), through implementation of additional turbocharging equipment (a so-called EGR-pump) ${ }^{[7-9]}$, or through application of turbocharger with variable nozzle turbine.

On the basis of this background, the purpose of this paper is to reduce emissions of a turbocharged diesel engine by VNT and EGR technologies. In this case the recirculated gas was taken from the upstream of the turbine to the downstream side of the compressor.

\section{EXPERIMENTAL APPARATUS AND PROCEDURE}

\section{A. Experimental apparatus}

In this paper, a number of innovations had been developed specifically to accomplish EGR system and deliver optimum performance. They included a new EGR valve, to regulate the recirculation of exhaust gases; an EGR cooler, to reduce the temperature of exhaust gas; a new variable nozzle turbine (Fig.1), to provide the pressure necessary to drive the recirculated gases into the intake pipe; a venturi-pipe (Fig.2) , to combine inlet air and cooled exhaust gases prior to introduction into the cylinder. 


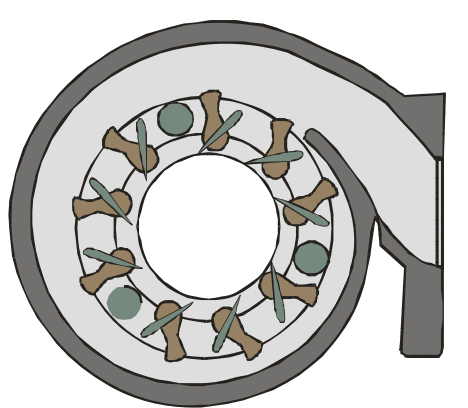

Fig.1 Schematic description of VNT

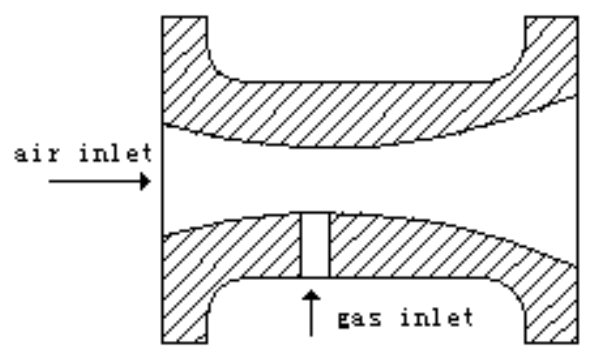

Fig. 2 Schematic description of venturi-pipe

The VNT turbocharger adjusts the gases cross section at the inlet of the turbine wheel in order to optimize turbine power with the required load. Instead of using one nozzle to accelerate the exhaust gases towards the turbine wheel, it has a ring of 9 variable vanes. As the vanes are rotated, they change the area of the nozzles that the exhaust must pass through.. An electric-liquid proportional valve was used to regulate the vanes position of the VNT. The smaller the nozzle area brings about the faster the gas velocity, the more turbine power, the more boost. At the other extreme the vanes can open fully when boost is not needed, with the resulting reduction in exhaust restriction.

Fig.2 shows a schematic description of the venturi pipe. The ventrui pipe was designed specially and it wouldn't affect the performance of the engine. The flow area reaches the minimum at the position of throat. The exhaust gases enter the throat and mix with the inlet air.

The engine is an inline 4-cylinder turbocharged direct injection diesel engine. The parameters of the engine are described in Table1. The base-line engine used a wastegate turbocharger with constant nozzle area.

The experimental apparatus are shown in Table 2. The torque of the engine is measured directly by the PECD 9400 dynamometer. The EGR rate and concentrations of $\mathrm{NO}_{\mathrm{x}}$ are measured by a MEXA-7000EGR emission analyzer, and the smoke emissions are tested by a fullautomated fqd-102A smoke meter.
Table 1 Engine specifications

\begin{tabular}{ll}
\hline Specification & Value \\
\hline Type & DI TCI \\
Cylinder Numbe & 4 \\
Bore $\times$ Stroke & $98 \times 105 \mathrm{~mm}$ \\
Displacement & $3.168 \mathrm{~L}$ \\
Compress ratio & $18: 1$ \\
Swirl ratio & 2.2 \\
Maximal torque/speed & $265 \mathrm{~N} . \mathrm{m} / 2000 \mathrm{rpm}$ \\
Rated Power & $81.5 \mathrm{~kW} / 3400 \mathrm{rpm}$ \\
Turbocharger & TB28 \\
\hline
\end{tabular}

Table 2 Test equipment of experiment

\begin{tabular}{ll}
\hline \multicolumn{1}{c}{ Equipment } & Type \\
\hline Test control instrument & EIM301D \\
dynamometer & PECD 9400 \\
EGR analyzer & MEXA-7000EGR \\
Emission analyzer & MEXA-7000EGR \\
Digital smoke & FQD-102A \\
Air flow-meter & sensycon \\
\hline
\end{tabular}

\section{B. Procedures}

In this paper, a turbocharger with VNT was installed on the test engine instead of the conventional turbocharger. The optimal vanes position was decided in every operating point through experiment. EGR experiment was based on VNT system. The schematic description of experiment is shown in Fig.3.

Fig. 4 shows the pressure before turbine and after compressor at full load operating points of the engine. As can be seen in Fig.4, the pressure after turbine is higher than that of before compressor between 1750rpm and 2750rpm, it means that EGR is impossible in these operating points. With applying of VNT and venturi-pipe, the pressure difference problem was solved.

The EGR rate was varied by controlling the opening degree of the EGR valve. The EGR rate was obtained from the measured $\mathrm{CO}_{2}$ concentration $\left[\mathrm{CO}_{2}\right]$ at the inlet manifold, at the exhaust, and the ambient atmosphere ${ }^{[6,10]}$.

$$
E G R \%=\frac{C O_{2 \text { int }}-C O_{2 a m b i e n t}}{C O_{2 e x t}-C O_{2 \text { ambient }}}
$$

In this paper, the performance of the engine was optimized with using a turbocharger with VNT. The performance and emissions characteristics of the engine with the vanes position at full load of the engine were investigated. The larger the vanes position, the smaller the flow area of the turbine, more air enters the engine. The more the inlet air, the larger the boosting rate. Different EGR rates were gotten when the EGR valve was opened to different degree. The EGR rate can be varied for the EGR method the base turbocharger was replaced with a VNT turbocharger. Then the EGR rate was varied by changing the turbine nozzle area. The EGR effects on the performance and emissions characteristics had been 
investigated VNT and venturi-pipe system provided the suitable pressure gradient for EGR flow. How the VNT system affects the EGR system had been investigated.

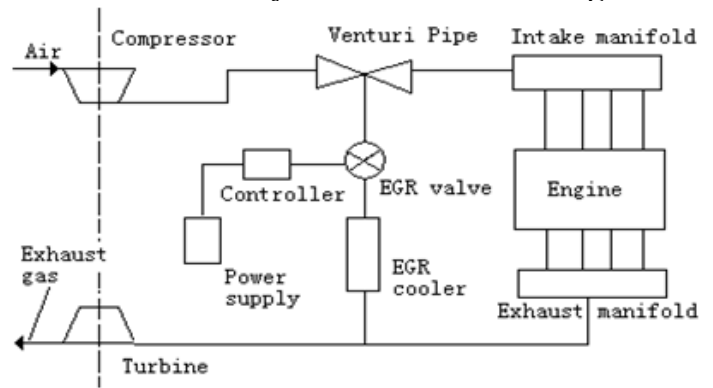

Fig.3 Schematic description of experiment

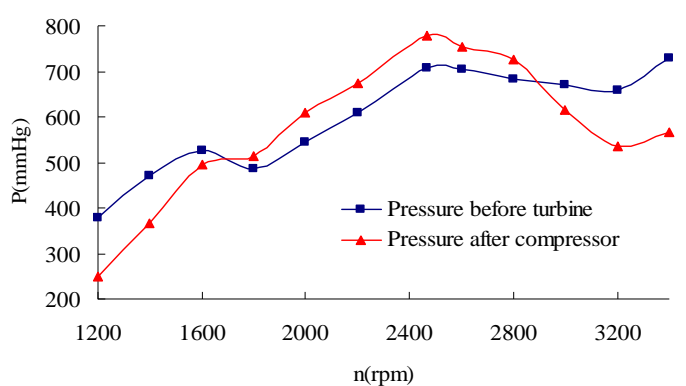

Fig. 4 The pressure before turbine and after compressor at full load operating points of the engine

\section{EXPERIMENTAL RESULTS AND DISCUSSION}

\section{A. Effects of VNT on the engine}

1). Comparison of VNT with conventional turbocharger

The performance and emissions of diesel engine equipped with conventional turbocharger were compared with that of engine equipped with VNT. Figs.(5-6) are the comparison of performance and emissions between VNT and conventional turbocharger(CT).

It is known from Fig.5 that the torques of engine equipped with VNT are larger than that of engine equipped with CT at all engine speed range. The increasing of torques is more obvious at low speeds. At the speed of 1200rpm, the torque of the engine with VNT at full load is $226 \mathrm{Nm}$, which is $35 \mathrm{Nm}$ larger than that of the original engine. The torque is increased by $18.3 \%$ by using VNT. At the speed of $1400 \mathrm{rpm}$, the torque is increased by $16.3 \%$ at full load point.

According to Fig.6, the BSFC at full load operating points of the engine with VNT is lower than that of engine with CT at all speed range. It is more obviously at high speeds. At the speed of 3400rpm, the BSFC of the engine with VNT is $247.9 \mathrm{~g} / \mathrm{kWh}$. It is reduced by $4.1 \%$ than that of original engine, which is $258.5 \mathrm{~g} / \mathrm{kWh}$.

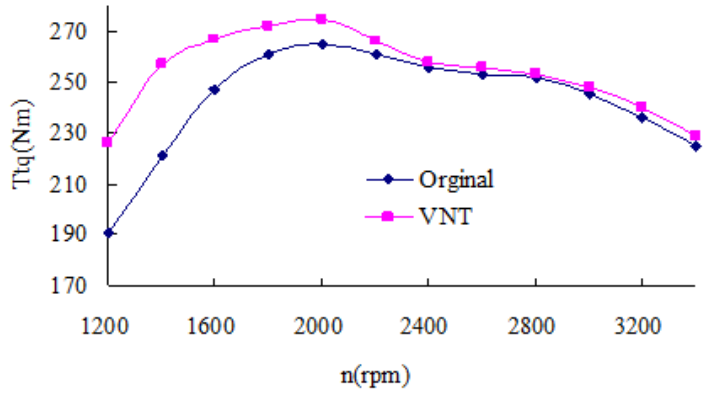

Fig. 5 Comparison of torque

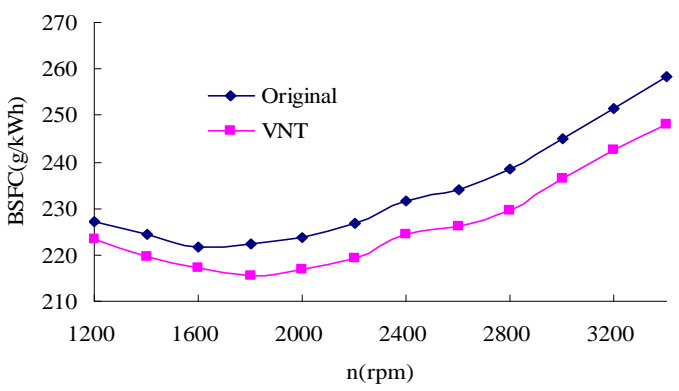

Fig.6 Comparison of BSFC

2). The performance of engine with VNT

Fig.7 shows comparison the general performance of the original engine with VNT engine, it can be found that the fuel consumption of VNT is lower than that of original engine. Take the fuel consumption contour line of 230 $\mathrm{g} / \mathrm{kWh}$ as an example, the largest engine speed is 2300rpm in the original engine, it is improved to 2800rpm in VNT engine. It means that the engine can get better fuel consumption by using of VNT at medium and high speeds. The speed of lowest fuel consumption in original engine is lower than that of VNT engine. It is difficult to get good performance both at low speed and at high speed when matching wasted gate turbocharger. The engine with VNT can get a good performance at all speed range.

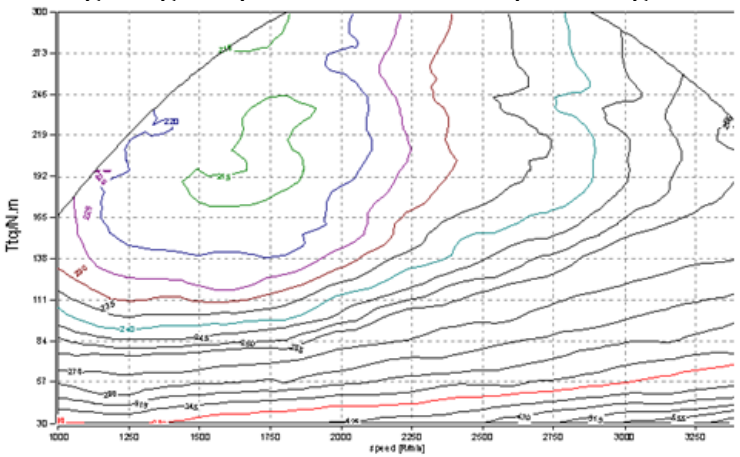




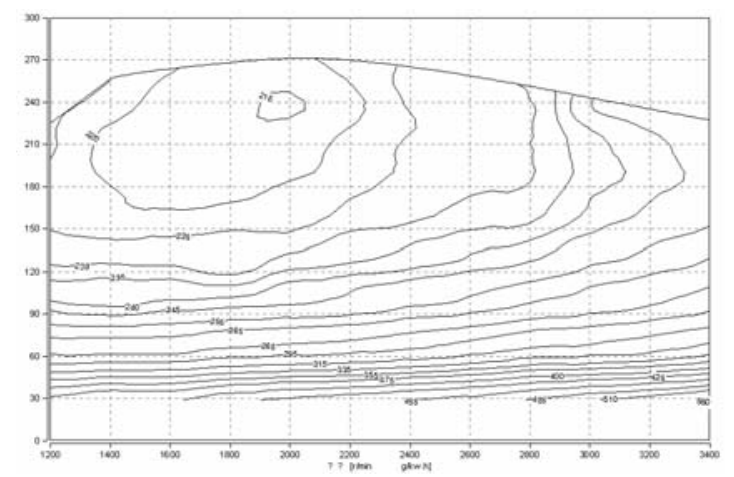

Fig.7 Comparison the general performance of the original engine with VNT engine

\section{B. Effects of EGR on the engine}

Effects of EGR rate and emissions of the engine were investigated. Different operating points had been tested. Take the speed of 2000rpm as an example, Fig.8 (a-b) are EGR rate on $\mathrm{NO}_{\mathrm{X}}$ emissions and smoke respectively at different loads.

1). Effects of EGR rate on emissions of the engine

Figs.8(a) and (b) show the effects of EGR rate on $\mathrm{NO}_{\mathrm{X}}$ and smoke of the engine at different loads. The EGR rate has greatly affected $\mathrm{NO}_{\mathrm{X}}$ and smoke. At $10 \%$ load, the smoke is at a very low level. It keeps constant with increasing of EGR rate. While the EGR rate has greatly effects on $\mathrm{NO}_{\mathrm{X}}$ emissions, it is reduced by $22.6 \%$, from $350 \mathrm{ppm}$ to $271 \mathrm{ppm}$. At this operating point, in order to achieve the best engine performance, the optimal EGR rate should be largest EGR rate. At 50\% load, when the EGR rate is zero, the $\mathrm{NO}_{\mathrm{X}}$ is $715 \mathrm{ppm}$, but when the EGR rate arrives to $15.1 \%$, the $\mathrm{NO}_{\mathrm{X}}$ turns to $375 \mathrm{ppm}$. In this case, the reduction rate is $47.6 \%$. On the contrary, the smoke is increased from 0.7BSU to 1.5BSU. For choosing the optimal EGR rate, the trade-off relation between $\mathrm{NO}_{\mathrm{X}}$ and smoke must be considered. At full load, $\mathrm{NO}_{\mathrm{X}}$ is reduced more rapidly with the increasing of EGR rate, it is $1160 \mathrm{ppm}$ at zero EGR rate, and it reduces to 680ppm at the largest EGR rate, the largest EGR rate is only 6.7\% at this operating point, the reduction of $\mathrm{NO}_{\mathrm{X}}$ emissions is $41.4 \%$. At the same time the smoke is increased from 1.7 BSU to 3.4 BSU.

(a)

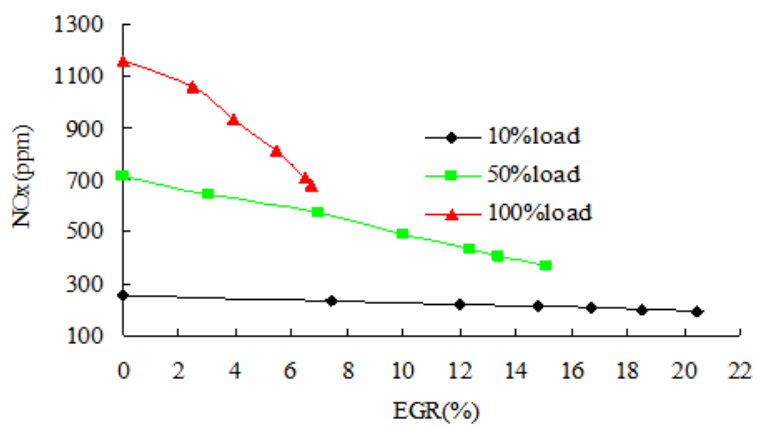

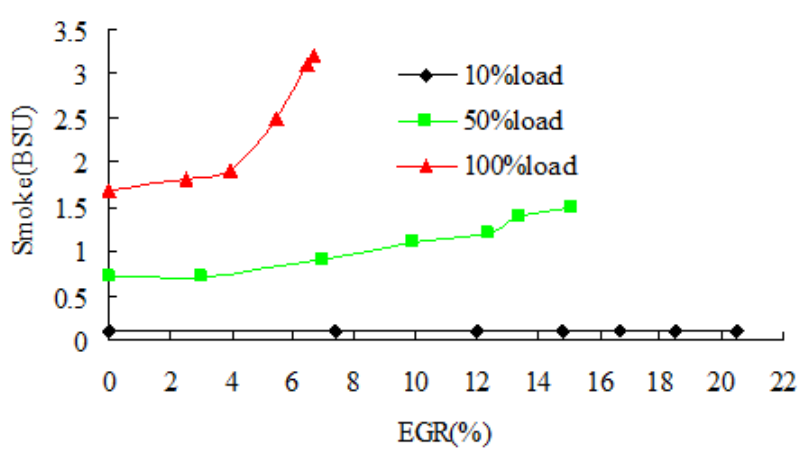

(b) Smoke

Fig. 8 Effects of EGR rate on $\mathrm{NO}_{\mathrm{X}}$ emission and the smoke

2). Effects of Optimal EGR rate on the performance and emission of the engine

Fig.9(a-d) shows the comparison of performance and emissions of the engine between optimal EGR and without EGR at the speed of 2000rpm, the optimal rate of each load at the speed of 2000rpm are listed in table3.

Table 3 Optimal EGR rate

\begin{tabular}{|c|c|c|c|c|c|}
\hline Load(\%) & 10 & 25 & 50 & 75 & 100 \\
\hline EGR(\%) & 20.5 & 18.3 & 10 & 7.2 & 2.4 \\
\hline
\end{tabular}

As shown in this figure, the effect of EGR on the torque variation is not appeared when the load is lower than $50 \%$, but if had a bad effect on the engine torque when the load is larger than $50 \%$.

The fuel consumption is decreased slightly at low load, while it is increased at high load.

The reduction of $\mathrm{NO}_{\mathrm{X}}$ emission is obviously at different loads.

The smoke does not change at the low load, but it increases with the increase of engine load.

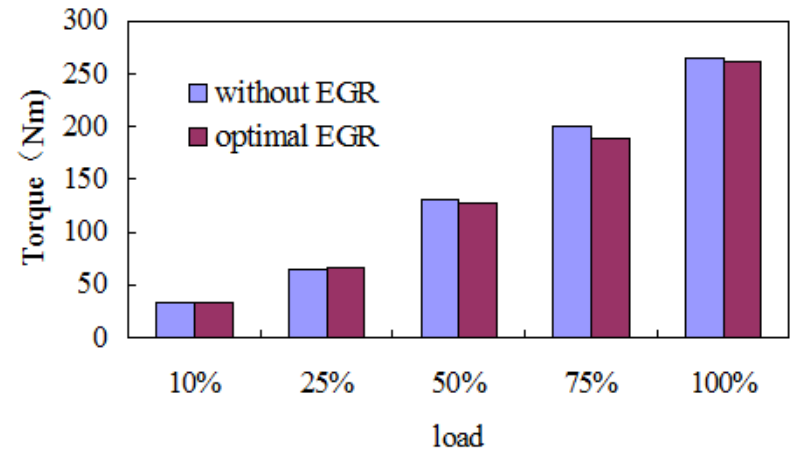

(a) Torque

(a) $\mathrm{NO}_{\mathrm{X}}$ 


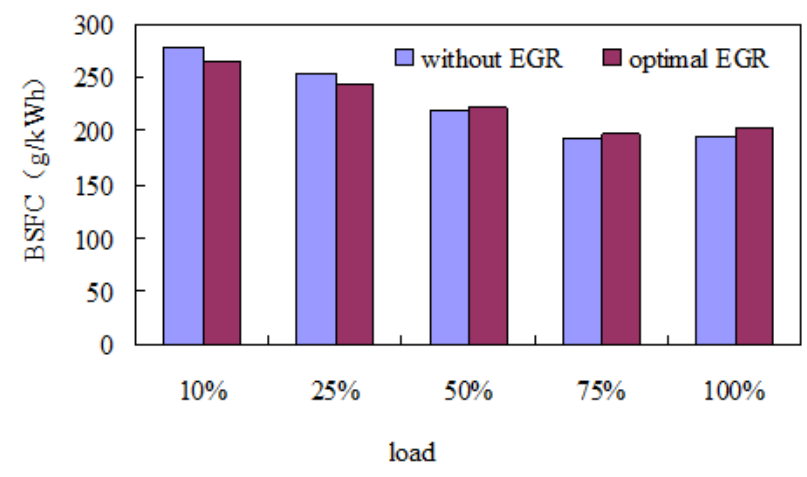

(b) BSFC

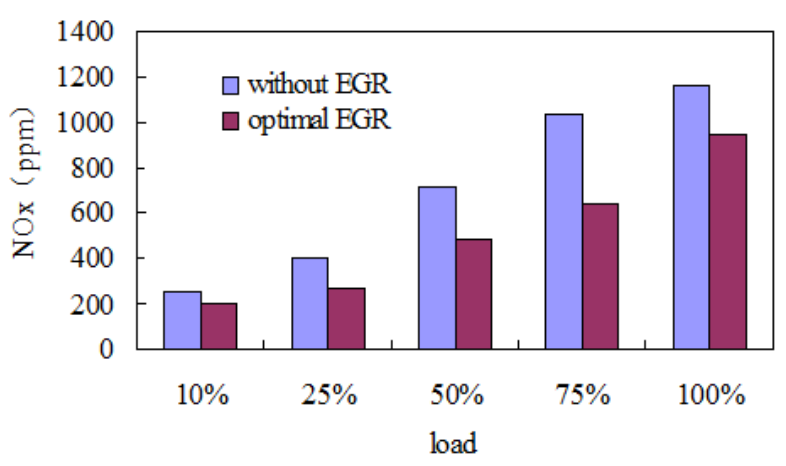

(c) NOX

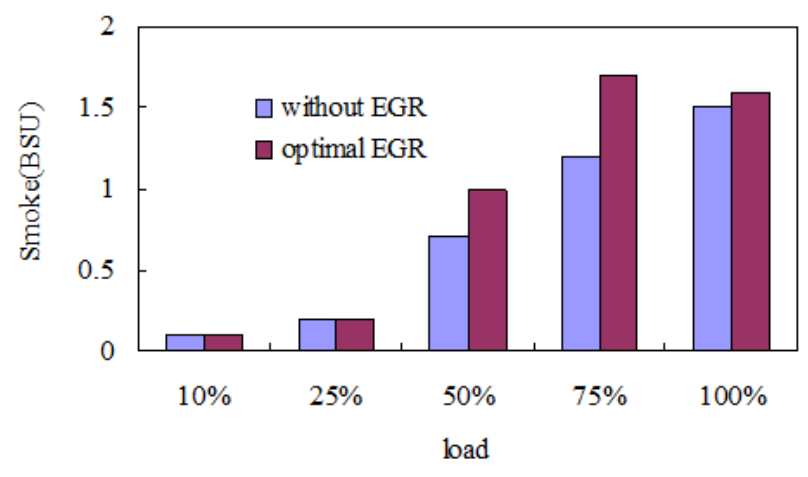

d) Smoke

Fig.9 $(\mathrm{a} \sim \mathrm{d})$ Comparison the performance and emissions of the engine between optimal EGR rate and without EGR at the speed of 2000rpm

\section{Effects of VNT on EGR system}

Fig.10 shows that the pressure before turbine is increased with the increasing of engine speed. The pressure almost keeps in linear relation with the speed in original engine. It is $125 \mathrm{mmHg}$ at the speed of 1200rpm, and it reaches $830 \mathrm{mmHg}$ at the speed of 3400rpm, which shows that the increasing of pressure is mainly affected by speed. For the engine matched with VNT, the pressure before turbine is mainly affected by the vanes position, the pressure curve keeps flat with the speed increasing, it is $506 \mathrm{mmHg}$ at the speed of $1200 \mathrm{rpm}$, and it turns to $655 \mathrm{mmHg}$ at the speed of 3400rpm. the increasing is slightly. When the speed is larger than 2800rpm, the pressure of VNT is lower than that of CT. While the pressure before turbine of VNT is greatly higher than that of CT at low and medium speeds.

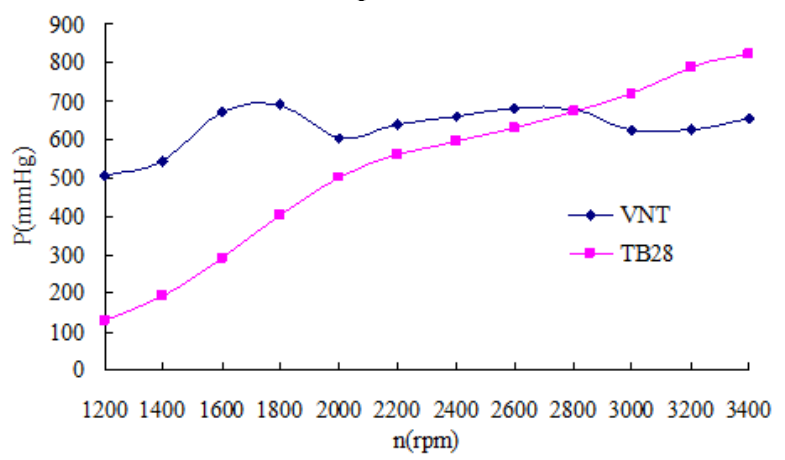

Fig.10 Comparison of pressure before-turbine between VNT and CT at full loads

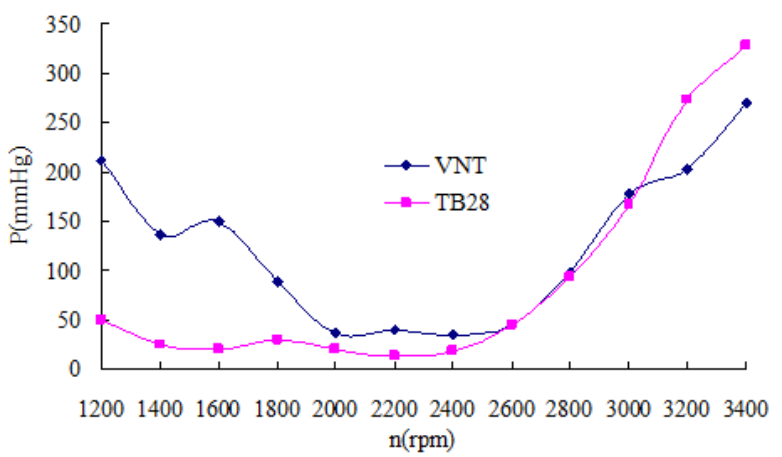

Fig.11 Comparison of pressure difference between VNT and $\mathrm{CT}$ at full loads

Fig.11 shows that the pressure difference between before-turbine and after-compressor is reduced with the increasing of speed. It reaches its minimum when the speed is between 2000rpm and 2400rpm. At the speed of 1200rpm, the pressure difference of VNT is $211 \mathrm{mmHg}$; the pressure difference of CT is $50 \mathrm{mmHg}$. The pressure difference in CT changes a little with the speed increasing when the speed is lower than 2400rpm. The pressure difference of VNT is less than that of CT when the speed is larger than 3000rpm. It is known that the pressures before turbine are always higher than that of throat of venturi-pipe in all speed range. EGR can be easily acquired with using of VNT and venturi-pipe.

It is shown in Fig.12 (a-b), at low speed, the maximum EGR rate of VNT is much larger than that of CT. The maximum EGR rate of CT is affected by load. The maximum EGR rate is $17.7 \%$ at $25 \%$ load; it is $4.3 \%$ at $100 \%$ load. The maximum EGR rate in VNT is little affected by load. The maximum EGR rate is about $29 \%$ at different loads. Although the pressure difference between EGR valve is small at low speed, it can be adjusted in the engine equipped with VNT. At the speed of 2000rpm, the EGR rate in VNT is still larger than that of TB28. 


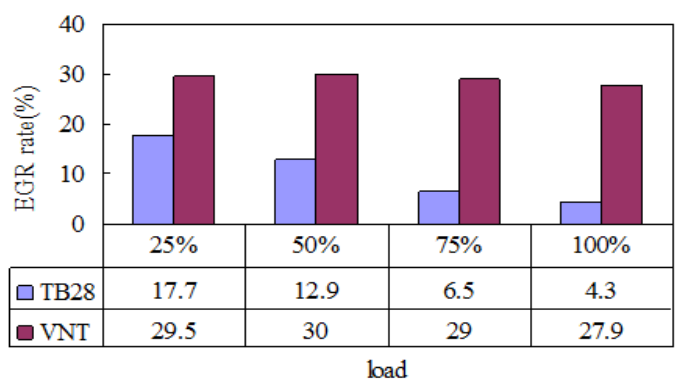

(a ) Comparison of maximum EGR rate at $1200 \mathrm{rpm}$

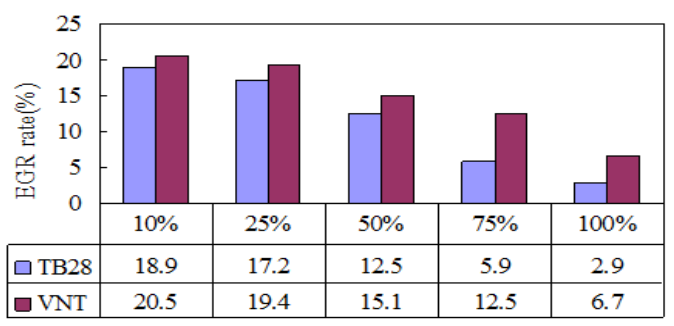

load

(b) Comparison of maximum EGR rate at 2000rpm

Fig.12 Comparison of maximal EGR rate between CT and VNT

Fig.13(a-b) shows the comparison of $\mathrm{NO}_{\mathrm{X}}$ reduction by maximum EGR rate between $\mathrm{CT}$ and VNT. At the speed of $1200 \mathrm{rpm}$, the $\mathrm{NO}_{\mathrm{X}}$ of the original is $1375 \mathrm{ppm}$ at full load; it is reduced to 1051ppm when the EGR rate reaches the maximum $4.3 \%$ with applying of CT. For the engine matched with VNT, the maximum EGR rate at this operating point is increased to $27.9 \%$, the $\mathrm{NO}_{\mathrm{X}}$ emission is reduced to $456 \mathrm{ppm}$, comparing with that of zero EGR, it has reduced $66.8 \%$. Of course, EGR has a bad effect on the torque and BSFC and smoke of the engine. The EGR reduces $\mathrm{NO}_{\mathrm{X}}$ emissions by the reduction of intake air. It shows the same trend as the engine at speed of 2000rpm.. It can be concluded that the $\mathrm{NO}_{\mathrm{X}}$ emissions can be reduced to a lower level with the using of VNT.

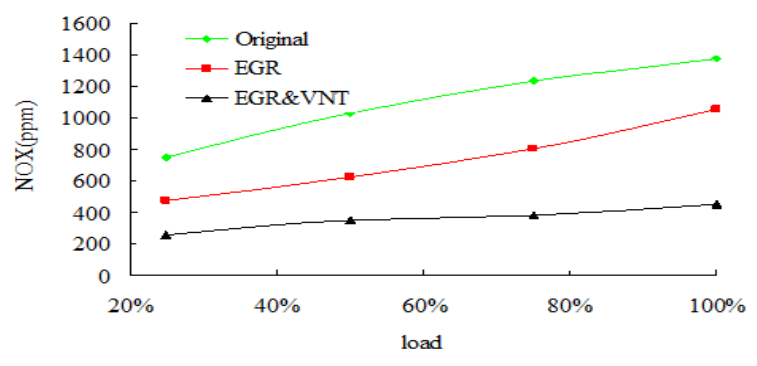

(a ) Comparison of NOx reduction at 1200rpm

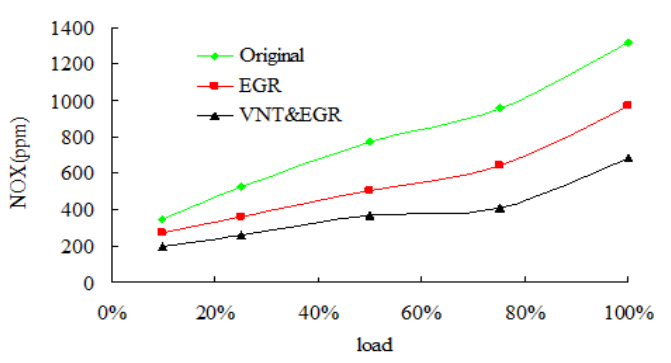

(b) Comparison of $\mathrm{NOx}$ reduction at $2000 \mathrm{rpm}$

Fig.13 Comparison of $\mathrm{NO}_{\mathrm{X}}$ reduction by EGR between TB28 and VNT

\section{CONCLUSIONS}

The following conclusions can be drawn from this study :

1) The engine performance is improved by using a turbocharger with variable nozzle turbine. The torques of the engine at low speeds were improved largely. The fuel consumptions were reduced dramatically .The smoke was reduced greatly for the increasing of inlet air.

2) EGR can reduce the $\mathrm{NO}_{X}$ emissions of the engine greatly while maintaining competitive fuel economy. The reduction of $\mathrm{NO}_{\mathrm{X}}$ emission is larger at high load. While EGR has bad effects on BSFC and smoke of the engine at high load.

3) A suitable pressure gradient for EGR flow can be established using a turbocharger with variable nozzle turbine. The scope of EGR rate is extended; The $\mathrm{NO}_{\mathrm{X}}$ emissions of the engine can be reduced to a lower level by EGR system based on VNT.

\section{REFERENCES}

[1] Heywood, J. B.(1988). Internal Combustion Engine Fundamentals,p21-29.

[2] Such C, Needham J, Edwards S, Freeman H.(1995). Devlopment of Heavy-Duty Diesel Engines for Low Emissions Using Exhaust Gas Recirculation(EGR), IPC8, p37-46, No.128.

[3] Sun Wanchen, Zhu Changji, Liu Zhongchang, et al. EGR transient response characteristics of automotive diesel engine[J]. Automotive Engineering, 2007,29(4) :333-336(in Chinese)

[4] J. W. Girard, L. D. Gratz, J. H. Johnson, S. T. Bagley and D. G. Leddy, A study of the character and deposition rates of sulfur species in the EGR cooling system of a heavy-duty diesel engine, SAE 1999-01-3566 (1999).

[5] S. M. Min, D. Y. Chung, K. S. Hong, K. S. Lee, S. H. Song and K. M. Chun, Evaluation of SOF effect on EGR cooler fouling in light duty diesel engine, Annual Conference of KSAE (2010) 2010B0024.

[6] Yamada,T., Ikeya,N., and Kondoh,N.( 1998). New EGR system for heavy duty diesel engines. SAE Paper No. 980775,Int. Congress\&Exposition.

[7] Haiyong Peng, Yi Cui, Lei Shi, et al. Effects of exhaust gas recirculation (EGR) on combustion and emissions during cold start of direct injection (DI) diesel engine[J]. Energy, 2008, 33: 471479.

[8] Yang Shuai, Li Xiuyuan, Ying Qijia, et al. EGR rates optimization rule and experimental study about influence ofEGR rates on diese engine[J]. Transactions of the Chinese Society for Agricultural Machinery, 2006, 37(5): 29-33.(in Chinese)

[9] Joon Lee1 and Kyoungdoug Min2, et al. A study of the fouling characteristics of EGR coolers in diesel engines, Journal of Mechanical Science and Technology 28 (8) (2014) 3395 3401

[10] S. M. Min, D. Y. Chung, K. S. Hong, K. S. Lee, S. H. Song and K. M. Chun, Evaluation of SOF effect on EGR cooler fouling in light duty diesel engine, Annual Conference of KSAE (2010) 2010B0024. 